\title{
Effects of salicylic acid on photosynthetic activity and chloroplast morphology under light and prolonged darkness
}

\author{
P. POÓR ${ }^{*+}$, P. BORBÉLY*, N. BÓDI ${ }^{* *}$, M. BAGYÁNSZKI**, and I. TARI* \\ Department of Plant Biology, University of Szeged, H-6726 Szeged, Közép fasor 52, Hungary* \\ Department of Physiology, Anatomy and Neuroscience, University of Szeged, H-6726 Szeged, Közép fasor 52, \\ Hungary $^{* *}$
}

\begin{abstract}
Salicylic acid (SA) is a key component of plant defence, which exerts a concentration-dependent effect on photosynthesis under multi-faceted influence of light. Photosynthetic activities and chloroplast morphology were studied in tomato plants after treatment with a sublethal, $0.1 \mathrm{mM}$, and a cell death-inducing, $1 \mathrm{mM}$ concentrations of SA under normal photoperiod during light phase and after a prolonged dark phase. SA $(1 \mathrm{mM})$ decreased the maximal $\left(\mathrm{F}_{\mathrm{v}} / \mathrm{F}_{\mathrm{m}}\right)$ and effective quantum yields of PSII $\left[\mathrm{Y}_{(\mathrm{II})}\right]$ and PSI $\left[\mathrm{Y}_{(\mathrm{I})}\right]$ under both environmental conditions, however, the photoprotective processes were not significantly different between light and dark samples. Decrease in grana height, thylakoid dilation and deformation of lumen were also observed in the light. In contrast to illuminated samples, $0.1 \mathrm{mM} \mathrm{SA}$ decreased $\mathrm{Y}_{(\mathrm{II})}$ and $\mathrm{Y}_{(\mathrm{I})}$ after dark incubation, but nonphotochemical energy dissipation and cyclic electron flow increased, suggesting that the photoprotective mechanisms could be activated in plants exposed to prolonged darkness.
\end{abstract}

Additional key words: carotenoid; nonphotochemical quenching; photosystem II and I; soluble sugar; starch.

\section{Introduction}

Environmental factors exert an influence on growth and development as well as on stress responses of plants. In particular, light can alter plant developmental or defence responses and can induce new signalling and regulation pathways mediated by various hormones (Roberts and Paul 2006, Ballaré 2014), since the concentration and physiological effects of these compounds are modulated by day/night cycles and light quality (Griebel and Zeier 2008, Kazan and Manners 2011, Cerrudo et al. 2012, de Wit et al. 2013, Kegge et al. 2013). The changes in plant primary and secondary metabolism in the dark can alter the availability of current photosynthates, which determine the ability of plants to synthesize defence compounds during the dark period (Kangasjärvi et al. 2012, López-Goldar et al. 2016, Panchal and Melotto 2017). Concomitantly, many pathogens and insects can perceive these changes adapting their behaviour accordingly (Suárez-Vidal et al. 2017). Thus, the clarification of plant metabolism and stress responses regulated by defence hormones is particularly important under light deprivation.

Salicylic acid (SA) is one of the key components of plant defence signalling networks in local and systemic acquired resistance against many pathogens (Vos et al. 2013) but it induces acclimation to various abiotic stresses, too (Horváth et al. 2007, Hayat et al. 2010, Khan et al. 2015). As a stress-related signalling compound, SA plays an indirect or direct role in various physiological processes, including photosynthesis (Mateo et al. 2006, Janda et al. 2014). Based on several investigations, high concentration (1-5 mM) of exogenously applied SA induces stomatal closure and may therefore be expected to affect the rate of photosynthesis (Poór et al. 2011, Poór and Tari 2012). High concentration of SA caused a reduction in the net photosynthetic rate $\left(P_{\mathrm{N}}\right)$ and decreased the activity and protein content of Rubisco in barley plants (Pancheva et al. 1996, Pancheva and Popova 1998). Moreover, chlorophyll (Chl) and carotenoid (Car) contents were also declined after exposure to high concentrations of SA (Fariduddin et

$\overline{\text { Received }} 13$ March 2018, accepted 22 October 2018.

${ }^{+}$Corresponding author; phone/fax: +36-62-544-307, e-mail: poorpeti@bio.u-szeged.hu

Abbreviations: Car - carotenoids; $\mathrm{CEF}$ - cyclic electron flow; Chl - chlorophyll; $\mathrm{F}_{0}$ - minimal fluorescence yield in dark-adapted state; FM - fresh mass; $\mathrm{F}_{\mathrm{v}} / \mathrm{F}_{\mathrm{m}}-$ maximum quantum yield of PSII; HR - hypersensitive response; LEF - linear electron flow; $P_{\mathrm{N}}-$ net photosynthetic rate; $\mathrm{q}_{\mathrm{L}}$ - estimates the fraction of open PSII centres; $\mathrm{q}_{\mathrm{P}}$ - photochemical quenching; RC - reaction centres; ROS reactive oxygen species; SA - salicylic acid; TEM - transmission electron micrograph; $Y_{(I)}-$ effective quantum yield of PSI; $Y_{(I I)}-$ effective quantum yield of PSII; $\mathrm{Y}_{(\mathrm{CEF})}$ - yield of cyclic electron flow around PSI; $\mathrm{Y}_{(\mathrm{NA})}$ - the quantum yield of nonphotochemical energy dissipation in PSI due to acceptor side limitation; $\mathrm{Y}_{(\mathrm{ND})}$ - quantum yield of nonphotochemical energy dissipation in PSI due to donor side limitation; $\mathrm{Y}_{(\mathrm{NO})}$ - quantum yield of nonregulated nonphotochemical energy dissipation; $\mathrm{Y}_{(\mathrm{NPQ})}$ - quantum yield of regulated nonphotochemical energy dissipation.

Acknowledgements: We thank Bécs Attiláné for her excellent technical assistance. This work was supported by grant from the Hungarian National Scientific Research Foundation (OTKA PD112855). The authors declare that they have no conflict of interest. 


\section{al. 2003, Moharekar et al. 2003).}

Increasing SA concentrations resulted in a significant decrease in the maximum $\left(\mathrm{F}_{\mathrm{v}} / \mathrm{F}_{\mathrm{m}}\right)$ and effective quantum yields $\left(\Phi_{\text {PSII }}\right)$ of PSII and also in the photochemical quenching coefficient $\left(\mathrm{q}_{\mathrm{P}}\right)$, and an increase in the nonphotochemical quenching (NPQ) in tomato leaves and guard cells (Poór and Tari 2012). In another investigation, it was observed that PSII electron transport was more sensitive to high SA than PSI in SA-infiltrated tobacco leaves (Janda et al. 2012). Nevertheless, the effects of SA on PSI received less attention.

A treatment of barley by $1 \mathrm{mM} \mathrm{SA}$ not only decreased the PSII activity but also induced alterations in leaf anatomy and reduced the width of the adaxial and abaxial epidermis. In parallel with decreasing photosynthetic pigment contents, the chloroplast ultrastructure was also affected by high concentrations of SA. Swelling of grana thylakoids, coagulation of the stroma, and increase in chloroplast volume were observed in these samples (Uzunova and Popova 2000). On the other hand, many scientific reports indicated that SA in micromolar $(\mu \mathrm{M})$ concentration plays a pivotal role in the protection of the photosynthetic apparatus of plants that are exposed to several environmental stresses (Rivas-San Vicente and Plasencia 2011), such as cold (Janda et al. 2007), heat (Hayat et al. 2009), drought (Habibi 2012), salt (Poór et al. 2011) or heavy metal stress (Krantev et al. 2008). However, it can be concluded that the effect of SA depends on the applied concentration, on the duration and the mode of the application, on plant species, on developmental stage or on environmental conditions, such as the presence or quality of light (Hayat et al. 2010, Rivas-San Vicente and Plasencia 2011). Although, it was observed that accumulation of SA and the initiation of SA-mediated signalling pathways after pathogen infection are also lightdependent (Chandra-Shekara et al. 2006, Griebel and Zeier 2008, Goodspeed et al. 2012, Karpiński et al. 2013, Poór et al. 2017), the effects of SA on the photosynthetic apparatus and on the efficiency of photosynthesis after a prolonged dark period remained mostly unclear. At the same time, the SA-mediated changes in photosynthetic performance can markedly influence the defence responses of plants after pathogen infection in the dark (Cheng et al. 2016).

In this article, comparative analyses of PSII and PSI activities were carried out in fully expanded, mature leaves of tomato plants exposed to a sublethal $(0.1 \mathrm{mM})$ and a cell-death-inducing concentration $(1 \mathrm{mM})$ of SA in order to reveal the differences in these parameters in the light phase of a normal photoperiod and after a prolonged dark treatment. In addition, alterations in chloroplast function and morphology were also elucidated in response to SA.

\section{Materials and methods}

Plant material: Seeds of tomato plants (Solanum lycopersicum L. cv. Ailsa Craig) were germinated at $26^{\circ} \mathrm{C}$ for three days in the dark; the seedlings were subsequently transferred to perlite for two weeks. Plants were grown hydroponically afterwards in a controlled environment under PPFD of $200 \mu \mathrm{mol}$ (photon) $\mathrm{m}^{-2} \mathrm{~s}^{-1}$ (F36W/GRO lamps, Osram Sylvania, Danvers, MA, USA), with 12/12-h light (L)/dark (D) period, a day/night temperatures of $25 / 22^{\circ} \mathrm{C}$, and a relative humidity of $55-60 \%$ for eight weeks (Poór et al. 2011). Tomato plants $(n=36)$ were treated with $0.1 \mathrm{mM}$ or $1 \mathrm{mM}$ SA supplied in the nutrient solution and right afterwards they were divided into two groups which received either a normal photoperiod (12-h L/ 12-h D, light samples) or the prolonged dark period (24-h D, dark samples) treatment for the next $24 \mathrm{~h}$ at $25^{\circ} \mathrm{C}$. The experiments were conducted at the end of the 24-h incubation from 9 a.m. and were repeated three times. The samples were prepared from the second, fully expanded young leaves in three replicates $24 \mathrm{~h}$ after the different SA treatments under both conditions.

Chl $a$ fluorescence measurements and PSI activity: Chl $a$ fluorescence and P700 redox state were analysed with Dual-PAM-100 instrument (Heinz-Walz, Effeltrich, Germany) (Klughammer and Schreiber 1994). Leaves were dark-adapted for $20 \mathrm{~min}$ before the measurement of $\mathrm{F}_{0}$, the minimal fluorescence yield of the dark-adapted state, using weak measuring light when reaction centres (RC) are open. The maximal fluorescence in dark-adapted state $\left(\mathrm{F}_{\mathrm{m}}\right)$ was measured by applying a pulse $(800 \mathrm{~ms})$ of saturating light $\left[12,000 \mu \mathrm{mol}\left(\right.\right.$ photon) $\left.\mathrm{m}^{-2} \mathrm{~s}^{-1}\right]$. The leaves were then illuminated continuously with actinic light $\left[220 \mu \mathrm{mol}\right.$ (photon) $\left.\mathrm{m}^{-2} \mathrm{~s}^{-1}\right]$. After $20 \mathrm{~min}$, the lightadapted steady-state fluorescence $\left(\mathrm{F}_{\mathrm{s}}\right)$ was recorded and the maximum fluorescence level $\left(\mathrm{F}_{\mathrm{m}}{ }^{\prime}\right)$ in the light-adapted state was determined with saturating pulses. The actinic light was then turned off and the minimum fluorescence level in the light-adapted state $\left(\mathrm{F}_{0}{ }^{\prime}\right)$ was determined by illuminating the leaf with 3 -s far-red light [5 $\mu \mathrm{mol}$ (photon) $\mathrm{m}^{-2} \mathrm{~s}^{-1}$. The following Chl fluorescence parameters were calculated: the maximal quantum efficiency of PSII photochemistry in the dark-adapted state: $\mathrm{F}_{\mathrm{v}} / \mathrm{F}_{\mathrm{m}}=\left(\mathrm{F}_{\mathrm{m}}-\mathrm{F}_{0}\right) / \mathrm{F}_{\mathrm{m}}$; the effective quantum yield of PSII: $\mathrm{Y}_{(\mathrm{II})}=\left(\mathrm{F}_{\mathrm{m}}{ }^{\prime}-\mathrm{F}_{\mathrm{s}}\right) / \mathrm{F}_{\mathrm{m}}{ }^{\prime}$; the quantum yield of non-regulated energy dissipation: $\mathrm{Y}_{(\mathrm{NO})}=\mathrm{F}_{\mathrm{s}} / \mathrm{F}_{\mathrm{m}}$, and the quantum yield of regulated energy dissipation: $\mathrm{Y}_{(\mathrm{NPQ})}=1-\mathrm{Y}_{(\mathrm{II})}-\mathrm{Y}_{(\mathrm{NO})}$ (Genty et al. 1989, Kramer et al. 2004).

The quantum yield of PSI $\left[\mathrm{Y}_{(\mathrm{I})}\right]$ is defined by the proportion of the overall $\mathrm{P} 700$, which is reduced at a given state and not limited by the acceptor side. It was calculated from the complementary PSI quantum yields of nonphotochemical energy dissipation: $\mathrm{Y}_{(\mathrm{I})}=1-\mathrm{Y}_{(\mathrm{ND})}-\mathrm{Y}_{(\mathrm{NA})}$, where $\mathrm{Y}_{(\mathrm{ND})}$ and $\mathrm{Y}_{(\mathrm{NA})}$ are the quantum yields of nonphotochemical energy dissipation in PSI due to donor and acceptor side limitations, respectively. $\mathrm{Y}_{(\mathrm{ND})}=1-\mathrm{P} 700_{\text {red }}$ and $\mathrm{Y}_{(\mathrm{NA})}=\left(\mathrm{P}_{\mathrm{m}}-\mathrm{P}_{\mathrm{m}}{ }^{\prime}\right) / \mathrm{P}_{\mathrm{m}}$. $\mathrm{P}_{\mathrm{m}}$ was determined by applying a saturation pulse after pre-illumination with far-red light and it represents the maximal change of the P700 signal from a fully reduced state to a fully oxidized state. $\mathrm{P}_{\mathrm{m}}$ ' was defined in the same way as the fluorescence parameter $F_{m}$ '. $\mathrm{P} 700_{\text {red }}$ was determined in a given state with the help of a saturation pulse and it represents the maximal change of the P700 signal in a given light state (Klughammer and Scheiber 1994, Schreiber and Klughammer 2008, Zhang et al. 2014). The yield of cyclic electron flow (CEF) around PSI $\left[\mathrm{Y}_{(\mathrm{CEF})}\right]$ is calculated as $\mathrm{Y}_{(\mathrm{CEF})}=\mathrm{Y}_{(\mathrm{I})}-\mathrm{Y}_{(\mathrm{II})}$. The ratio 
of the quantum yield of $\mathrm{CEF}$ to the linear electron flow (LEF) is calculated as $\mathrm{Y}_{(\mathrm{CEF})} / \mathrm{Y}_{(\mathrm{II})}=\left[\mathrm{Y}_{(\mathrm{I})}-\mathrm{Y}_{(\mathrm{II})}\right] / \mathrm{Y}_{(\mathrm{II})}$ (Lei et al. 2014).

Photosynthetic pigment analysis: For pigment analysis, a two-step extraction was applied. Leaf samples of $25 \mathrm{mg}$ were homogenized in $1 \mathrm{ml}$ of $100 \%(\mathrm{v} / \mathrm{v})$ cold acetone, and extracted for $24 \mathrm{~h}$ in the dark at $4^{\circ} \mathrm{C}$. Samples were centrifuged $\left(12,000 \times g\right.$ for $15 \mathrm{~min}$ at $\left.4^{\circ} \mathrm{C}\right)$. The pellet was extracted again with $1 \mathrm{ml}$ of cold acetone/Tris buffer solution $(80: 20, \mathrm{v} / \mathrm{v}, \mathrm{pH}=7.8)$ for $24 \mathrm{~h}$ in the dark at $4^{\circ} \mathrm{C}$. After centrifugation $\left(12,000 \times \mathrm{g}, 15 \mathrm{~min}, 4^{\circ} \mathrm{C}\right)$, the supernatants were collected. The pigment content was measured by spectrophotometer (Kontron, Milano, Italy) and was calculated by the equations based on Lichtenthaler and Wellburn (1983).

Carbohydrate (soluble sugars and starch) analysis was performed according to Hansen and Møller (1975). Briefly, soluble sugars were extracted from grinded samples of 100 $\mathrm{mg}$ of fresh mass (FM) with $1 \mathrm{ml}$ of $80 \%$ ethanol at $80^{\circ} \mathrm{C}$ for $30 \mathrm{~min}$. The homogenate was centrifuged at $2,600 \times g$ for $10 \mathrm{~min}$ and the supernatant was used for determination of sugar content spectrophotometrically (Kontron, Milano, Italy) at $630 \mathrm{~nm}$ after reaction with anthrone using glucose (Normapur, VWR Int., Leuven, Belgium) dissolved in $80 \%$ ethanol as a standard. Then, the pellet was washed with $1 \mathrm{ml}$ of deionized water, digested with $1 \mathrm{ml}$ of $1.1 \% \mathrm{HCl}$ at $100^{\circ} \mathrm{C}$ for $30 \mathrm{~min}$, and centrifuged for 10 min at $2,600 \times g$. Starch concentration was determined spectrophotometrically at $630 \mathrm{~nm}$ with anthrone using starch (Normapur, VWR Int., Leuven, Belgium) dissolved in $1.1 \% \mathrm{HCl}$ as a standard.

Transmission electron microscopy: For post-embedding electron microscopy, leaf segments (5-6 mm) were fixed in $2 \%$ paraformaldehyde and $2 \%$ glutaraldehyde solution and then further fixed for $1 \mathrm{~h}$ in $1 \% \mathrm{OsO}_{4}$. After rinsing in buffer and dehydrating in increasing ethanol concentrations and acetone, they were embedded in Embed812 (Electron Microscopy Sciences, Hatfield, PA, USA). Embedded blocks were used to prepare semithin $(0.7 \mu \mathrm{m})$ sections, to select the area of interest, and also ultrathin $(70 \mathrm{~nm})$ sections, which were mounted on nickel grids. To investigate the effects of SA treatments on the structure of chloroplasts in upper palisade mesophyll layer, three grids per block were counterstained with uranyl acetate (Merck, Darmstadt, Germany) and lead citrate (Merck, Darmstadt, Germany) and were examined and photographed with a JEM 1400 transmission electron microscope (JEOL Ltd., Tokyo, Japan) (Talapka et al. 2016). Measurements were performed on digital photographs at a magnification of 20,000 $\times$ with the AnalySIS 3.2 program (Soft Imaging System GmbH, Münster, Germany). Thirty experimental groups per treatments were analysed.

Statistical analysis: The results are expressed as means \pm SE. After analyses of variance (ANOVA) a multiple comparison followed by Duncan's multiple range test was performed with SigmaPlot version 11 software
(Systat Software Inc., San Jose, CA, USA). Means were considered significant if $P \leq 0.05$.

\section{Results}

$\mathrm{F}_{\mathrm{v}} / \mathrm{F}_{\mathrm{m}}$ did not change after the treatment with $0.1 \mathrm{mM} \mathrm{SA}$, but it decreased significantly upon $1 \mathrm{mM} \mathrm{SA}$ treatment under both light and dark treatments (Fig. 1A). There were no significant changes in the $\mathrm{F}_{0}$ and $\mathrm{F}_{\mathrm{m}}$ parameters after SA treatments under the two environmental conditions (Fig. $1 B, C$ ). In contrast, $24 \mathrm{~h}$ of light deprivation caused a slight decrease in $\mathrm{q}_{\mathrm{L}}$, which was significant under $0.1 \mathrm{mM}$ SA treatment. Interestingly, this decrease in $\mathrm{q}_{\mathrm{L}}$ cannot be observed at the higher SA concentration (Fig. 1D).

Although $\mathrm{Y}_{\text {(II) }}$ was lower in control leaves kept in the dark compared to light controls, the differences between light and dark samples were not significant. However,

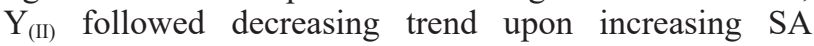
concentrations under both light and dark environment, which was significant already at $0.1 \mathrm{mM} \mathrm{SA}$ in the dark (Fig. 2A). This impact was more pronounced at $1 \mathrm{mM} \mathrm{SA}$, where the drop in $\mathrm{Y}_{\text {(II) }}$ was significant compared to both controls and to $0.1 \mathrm{mM}$ SA treated, illuminated plants (Fig. 2A). $\mathrm{Y}_{(\mathrm{I})}$ showed similar tendencies as $\mathrm{Y}_{(\mathrm{II})}$ during the experiments (Fig. $2 B$ ).

Although all SA treatments showed a slight increase in $\mathrm{Y}_{(\mathrm{NO})}$ compared to light-control samples, these increments were significant only upon the SA application combined with prolonged darkness (Fig. $2 C$ ). $\mathrm{Y}_{(\mathrm{NPQ})}$ also showed increasing tendencies $24 \mathrm{~h}$ after SA applications compared to light control (Fig. 2E). In contrast to normal photoperiod, $0.1 \mathrm{mM}$ SA caused a similar significant increment in $\mathrm{Y}_{(\mathrm{NPQ})}$ in the dark as $1 \mathrm{mM} \mathrm{SA}$ and this increment was significant compared to both kind of control groups, but there were no significant differences between the light and dark samples in this parameter upon $1 \mathrm{mM} \mathrm{SA}$ (Fig. 2E).

$\mathrm{Y}_{(\mathrm{ND})}$ followed the same trend as $\mathrm{Y}_{(\mathrm{NPQ})}$ : it increased significantly after $1 \mathrm{mMSA}$ Sreatment in both environments, while the application of $0.1 \mathrm{mM}$ SA raised $\mathrm{Y}_{(\mathrm{ND})}$ only in the dark (Fig. $2 D)$. In parallel, $\mathrm{Y}_{(\mathrm{NA})}$ decreased slightly during $0.1 \mathrm{mM}$ SA exposure, and significantly at the higher SA concentration under both light and dark conditions (Fig. $2 F$ ). However, the drop in $\mathrm{Y}_{(\mathrm{NA})}$ caused by $1 \mathrm{mM} \mathrm{SA}$ was more significant in the samples kept under normal light conditions, than that in the dark (Fig. $2 F$ ).

Compared to the light-control, $\mathrm{Y}_{(\mathrm{CEF})}$ and $\mathrm{Y}_{(\mathrm{CEF})} / \mathrm{Y}_{(\mathrm{II})}$ were enhanced by SA depending on the applied SA concentration and on the presence or absence of light (Fig. 3). $\mathrm{Y}_{\text {(CEF) }}$ was significantly elevated by $0.1 \mathrm{mM} \mathrm{SA}$ compared to both light and dark controls (Fig. 3A,B). However, $1 \mathrm{mM}$ SA induced $\mathrm{Y}_{(\mathrm{CEF})}$ significantly only under normal light conditions. Interestingly, this means that the enhancement of $\mathrm{Y}_{(\mathrm{CEF})}$ by the dark incubation ceased in the presence of the high SA concentration (Fig. 3A). Similar tendencies can be found in case of $\mathrm{Y}_{(\mathrm{CEF})} / \mathrm{Y}_{(\mathrm{II})}$ (Fig. $3 B$ ).

Nevertheless, $1 \mathrm{mM}$ SA did not cause a decline in the contents of photosynthetic pigments but increased the Chl $(a+b)$ (Fig. 4A) and Car content (Fig 4B) in the leaves of tomato after $24 \mathrm{~h}$ under normal photoperiod. At the same time, photosynthetic pigments did not change 

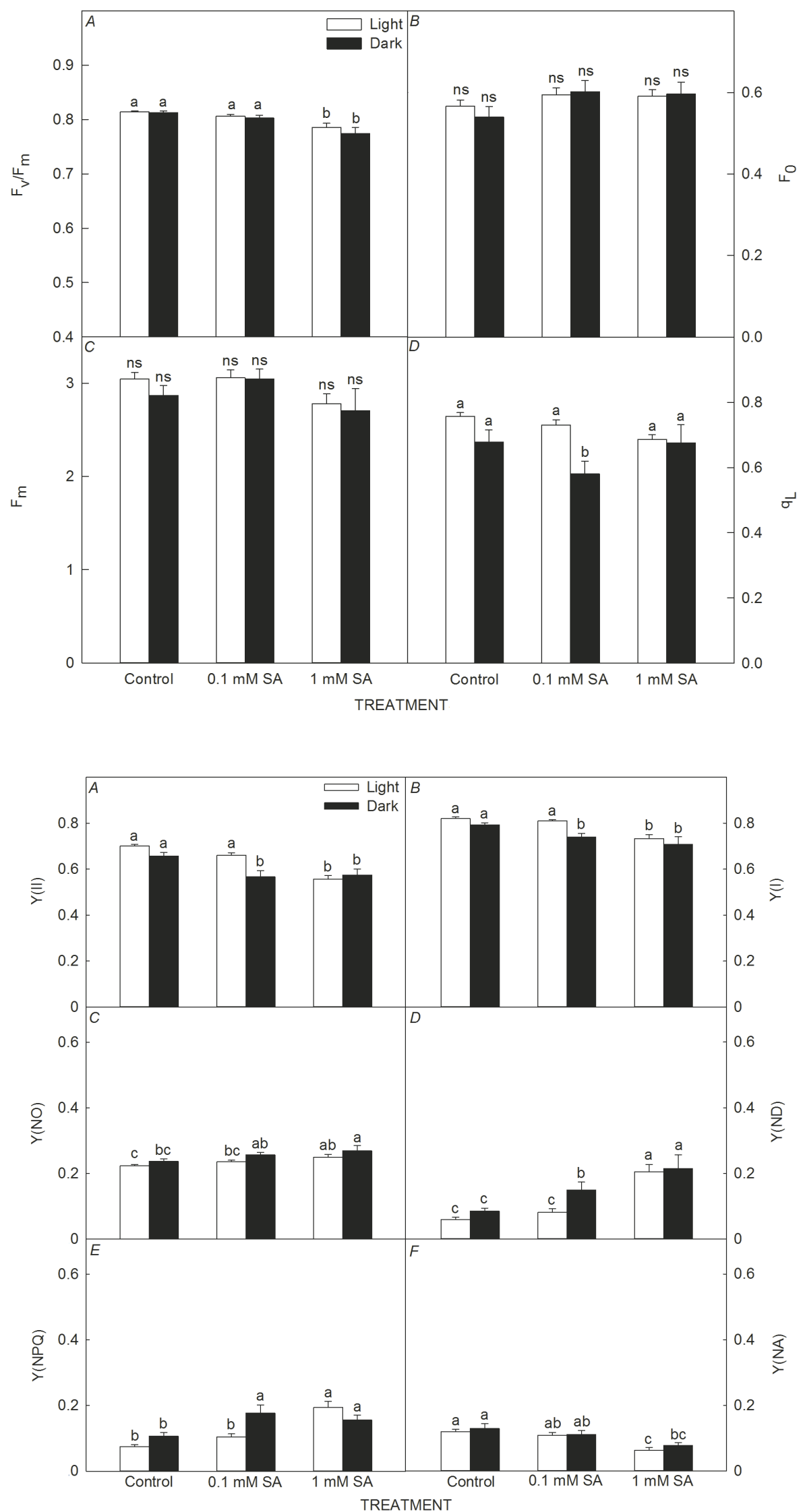

Fig. 1. Changes in the maximum quantum yield of PSII $\left[\mathrm{F}_{\mathrm{v}} / \mathrm{F}_{\mathrm{m}} ; A\right]$, minimal fluorescence yield of the dark-adapted state $\left[\mathrm{F}_{0} ; B\right]$, the maximal fluorescence in dark-adapted state $\left[\mathrm{F}_{\mathrm{m}} ; C\right]$, and the fraction of open PSII reaction centres $\left[\mathrm{q}_{\mathrm{L}} ; D\right]$ in fully expanded young leaves of tomato plants treated for $24 \mathrm{~h}$ with 0.1 or $1 \mathrm{mM}$ salicylic acid (SA) in the light or in the dark. Means \pm SE, $n=$ 12. Bars denoted by different letters are significantly different at $P \leq 0.05$ as determined by Duncan's multiple range test (ns - not significant).

Fig. 2. Changes in the effective quantum yield of PSII $\left[\mathrm{Y}_{(\mathrm{II})} ; A\right]$, the quantum yield of PSI $\left[\mathrm{Y}_{(\mathrm{I})} ; B\right]$, the quantum yield of nonregulated nonphotochemical energy dissipation $\left[\mathrm{Y}_{(\mathrm{NO})} ; C\right]$, the quantum yield of nonphotochemical energy dissipation in PSI due to donor side limitation [ $\mathrm{Y}_{(\mathrm{ND})}$; $D]$, the quantum yield of regulated nonphotochemical energy dissipation $\left[\mathrm{Y}_{(\mathrm{NPQ})} ; E\right]$, and the quantum yield of nonphotochemical energy dissipation in PSI due to acceptor side limitation $\left[\mathrm{Y}_{(\mathrm{NA})} ; F\right]$ in fully expanded young leaves of tomato plants treated for 24 $\mathrm{h}$ with 0.1 or $1 \mathrm{mM}$ salicylic acid (SA) in the light or in the dark. Means \pm SE, $n=12$. Bars denoted by different letters are significantly different at $P \leq 0.05$ as determined by Duncan's multiple range test. 


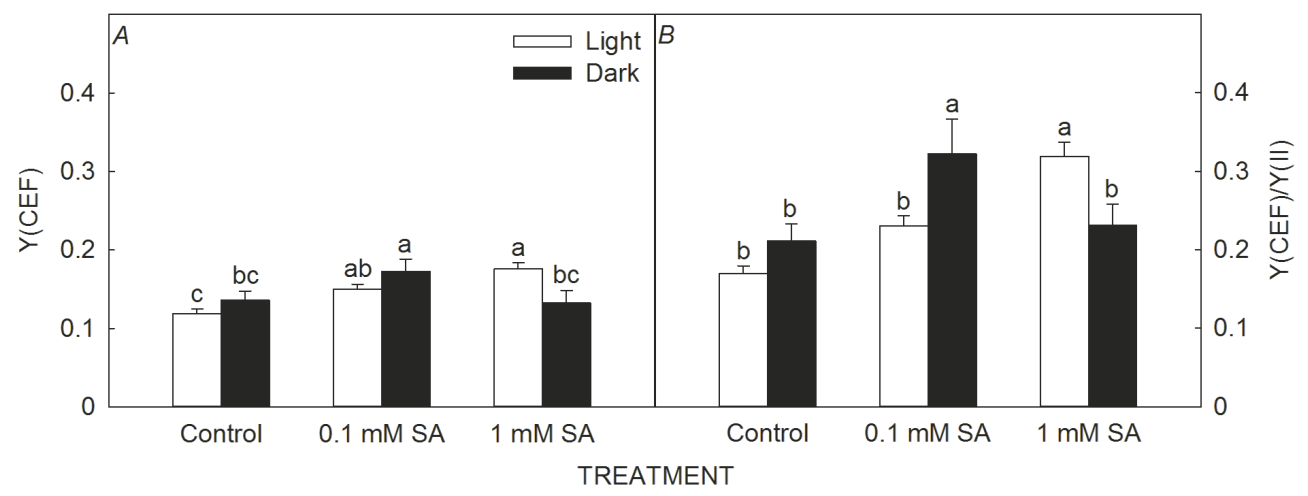

Fig. 3. Changes in the yield (Y) of cyclic electron flow (CEF) through PSI $\left[\mathrm{Y}_{(\mathrm{CEF})} ; A\right]$ and $\left.\mathrm{Y}_{(\mathrm{CEF})} / \mathrm{Y}_{(\mathrm{II})} ; B\right]$ in fully expanded young leaves of tomato plants treated for $24 \mathrm{~h}$ with 0.1 or $1 \mathrm{mM}$ salicylic acid (SA) in the light or in the dark. Means $\pm \mathrm{SE}, n=12$. Bars denoted by different letters are significantly different at $P \leq 0.05$ as determined by Duncan's multiple range test.

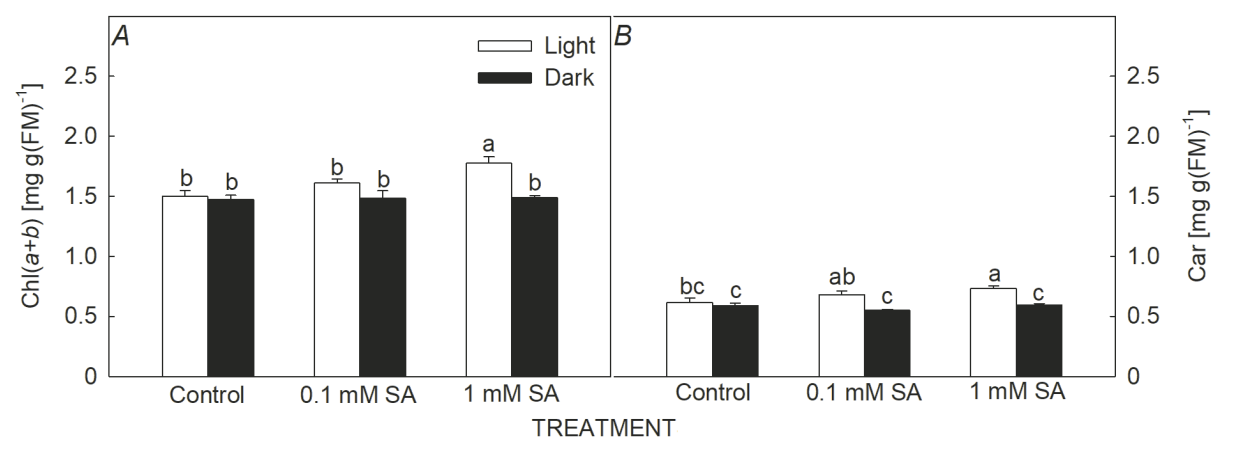

Fig. 4. Changes in the chlorophyll $(a+b)[\mathrm{Chl}(a+b) ; A]$ and carotenoids (Car) content $(B)$ of fully expanded young leaves of tomato plants treated for $24 \mathrm{~h}$ with 0.1 or $1 \mathrm{mM}$ salicylic acid (SA) in the light or in the dark. Means $\pm \mathrm{SE}, n=6$. Bars denoted by different letters are significantly different at $P \leq 0.05$ as determined by Duncan's multiple range test.

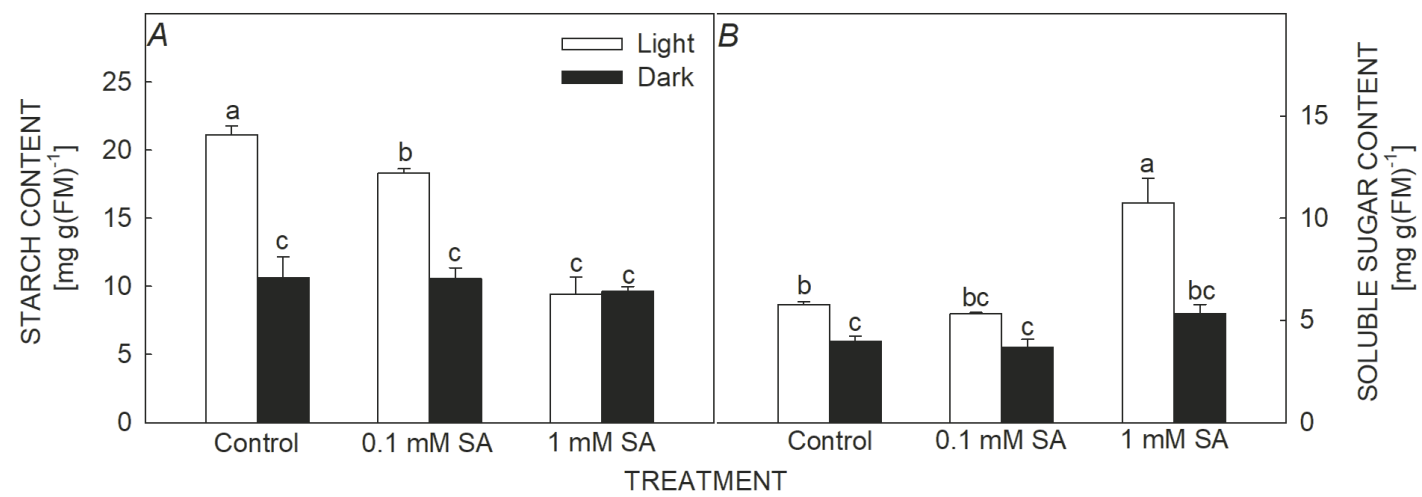

Fig. 5. Changes in the starch $(A)$ and soluble sugars content $(B)$ of fully expanded young leaves of tomato plants treated for $24 \mathrm{~h}$ with 0.1 or $1 \mathrm{mM}$ salicylic acid (SA) in the light or in the dark. Means $\pm \mathrm{SE}, n=6$. Bars denoted by different letters are significantly different at $P \leq 0.05$ as determined by Duncan's multiple range test.

significantly after the SA exposure in the dark (Fig. 4).

In order to detect the key products of photosynthesis after SA treatments, starch and soluble sugars contents were measured in the leaves of tomato after the SA exposure. The accumulation of soluble sugars and starch was severely reduced in the leaves after 24-h dark incubation (Fig. 5). SA treatments caused a stepwise decline in starch content (Fig. 5A), and in parallel increased soluble sugar content at $1 \mathrm{mM} \mathrm{SA}$ in the leaves kept under a normal photoperiod
(Fig. 5B). However, we did not find significant differences in starch and soluble sugar contents of tissues upon SA treatments under prolonged darkness.

To detect the effects of different concentrations of SA treatments on chloroplasts structure, transmission electron micrographs (TEMs) were used. TEMs of leaf sections revealed significant changes in the fine structure of chloroplasts (Fig. 6). Control samples kept in the light or in the dark showed only small and well-known cytological 


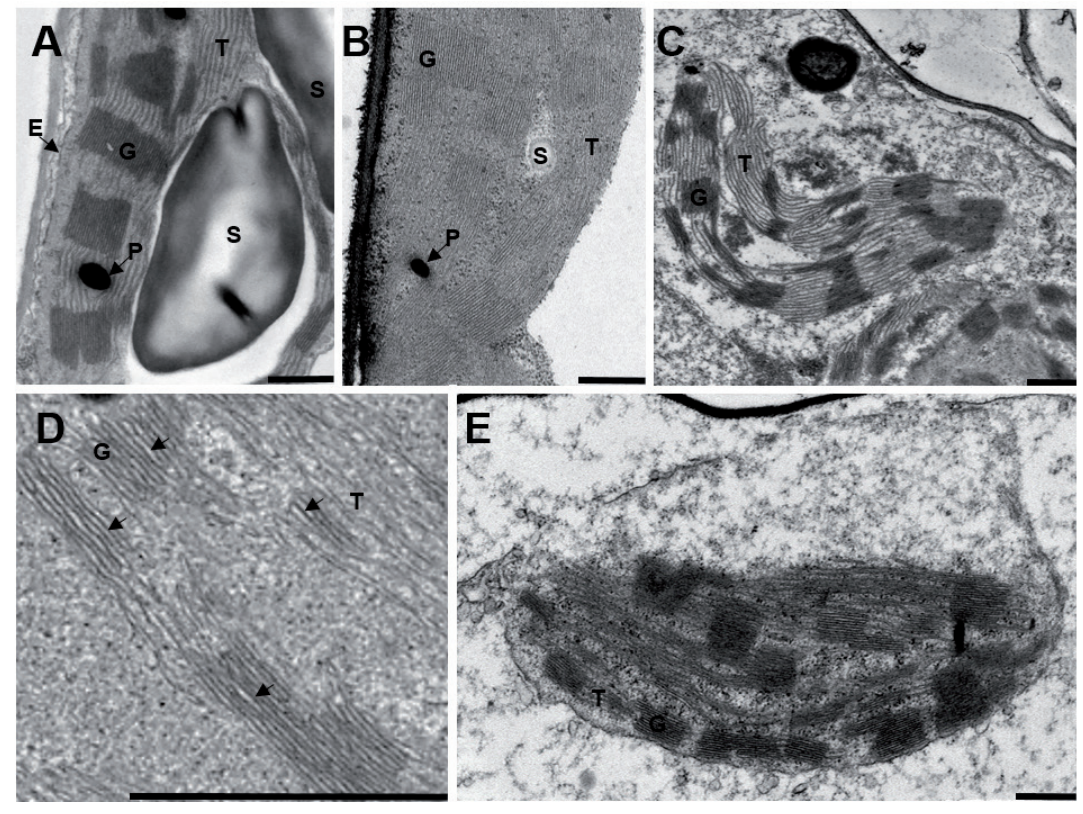

Fig. 6. Representative transmission electron micrographs (TEMs) of chloroplasts from palisade parenchyma cells of fully expanded young tomato leaves exposed to $1 \mathrm{mM}$ SA for $24 \mathrm{~h}$ in the light or in the dark. (A) Chloroplast with normal organization and structure from a control leaf in the light. (B) Chloroplast from a control leaf in the dark. (C) Low magnification of TEMs of chloroplasts in a $1 \mathrm{mM}$ SA-treated leaf in the light, where some chloroplasts were damaged. $(D)$ High magnification of TEMs of chloroplast in $1 \mathrm{mM}$ SA-treated leaf in the light with wavy grana and thylakoids (arrows). (E) Chloroplast in $1 \mathrm{mM} \mathrm{SA}$-treated leaf in the dark. $\mathrm{E}$ - chloroplast envelope, $\mathrm{G}$ - grana, $\mathrm{P}$ - plastoglobule, $\mathrm{S}$ - starch grain, $\mathrm{T}-$ thylakoids. $\mathrm{Bar}=500 \mathrm{~nm}$.

modifications in cell organelles or in chloroplast shape and structure (e.g. width of grana, the area of plastids) (Fig. 6A). Plastids from the control leaves in the light contained starch grains, but they were only rarely found in darktreated samples (Fig 6B). In the leaves treated with $1 \mathrm{mM}$ $\mathrm{SA}$, chloroplasts lost their normal structure and exhibited spherical, longish or curved shape (Fig 6C). Moreover, dilation of thylakoid membranes, an appearance of thylakoid vesicles, and long wavy deformed lumen were also observed in these SA-treated samples (Fig 6D). In contrast, $1 \mathrm{mM}$ SA induced vacuolisation of chloroplasts but not significant deformation of the lumen in the dark (Fig. 6E).

Based on the analysis of TEMs, the area of plastids was significantly higher in the light-control samples than after 24-h dark incubation (Fig. 7A). The area of chloroplasts depended on the presence of starch grains, which were observed in the samples under normal photoperiod. At the same time, SA treatments decreased the number of starch grains in these samples as a function of increasing concentration (Fig 7B). The area of plastids and the number of starch grains was very small compared to light samples and exhibited only slight changes upon SA treatments in the dark (Fig. 7A,B). Prolonged darkness increased significantly the height, but induced narrowing of grana in the chloroplasts of control plants (Fig. $7 C, D$ ). These changes in the ultrastructure were visualized in the ratio of height $(\mathrm{H})$ and width $(\mathrm{W})$ of grana (Fig. $7 E$ ). SA treatments decreased both parameters gradually at the applied concentrations, which were more significant in the dark-treated samples (Fig 7C,D). In contrast to the height of grana, SA application increased the height of the granal lumen, but it could be observed only in the light (Fig. 7F).

\section{Discussion}

The presence of light is one of the most important environmental factors, which is required for optimal growth and development of plants and can influence plant defence responses. The absence of light (e.g. night period or experimentally induced prolonged darkness) can alter the light-dependent signalling and regulation pathways and may induce new defence responses modulated by phytohormones (Ballaré 2014). SA is one of the key defence phytohormones and plays a crucial role in modulating immunity and disease response in plants (Loake and Grant 2007). The direct effects of SA on photosynthetic apparatus and the indirect effects on photosynthesis through the limitation of $\mathrm{CO}_{2}$ supply by regulating stomatal movements take an integral part of the plant immune responses and reduce pathogen invasion by decreasing the availability of photosynthates and by inducing hypersensitive reaction (HR) in the leaves (Muthamilarasan and Prasad 2013, Cheng et al. 2016). Effects of SA seem to be different in light or dark conditions (Takács et al. 2016, Poór et al. 2017). Moreover, the accumulation of SA is the highest in the dark period of the day $\left[\sim 0.1 \mu \mathrm{g}\right.$ (total SA) $\mathrm{g}^{-1}(\mathrm{FM})$ in tomato leaves]. It was found that jasmonate and salicylate accumulation patterns are regulated by the circadian clock with opposite phasing. Jasmonates peaked in the middle of the day while a peak of salicylates was found in the middle of the night (Goodspeed et al. 2012). In this aspect, the effects of high SA concentrations on photosynthetic apparatus and on chloroplast morphology in the dark can be especially important, because they can determine plant responses in the next light phase, especially during an infection.

It was demonstrated by our experiments that the effect of SA on chloroplast ultrastructure or on the Chl $a$ fluorescence and P700 redox state parameters exhibited concentration dependency and correlated well with the availability of light. It was found by our earlier experiments (Takács et al. 2016, Poór et al. 2017) that tomato plants were able to acclimate to $0.1 \mathrm{mM} \mathrm{SA}$, which thus can be considered as a sublethal concentration, but $1 \mathrm{mM}$ SA induced a HR-like cell death program in the leaf tissues, 


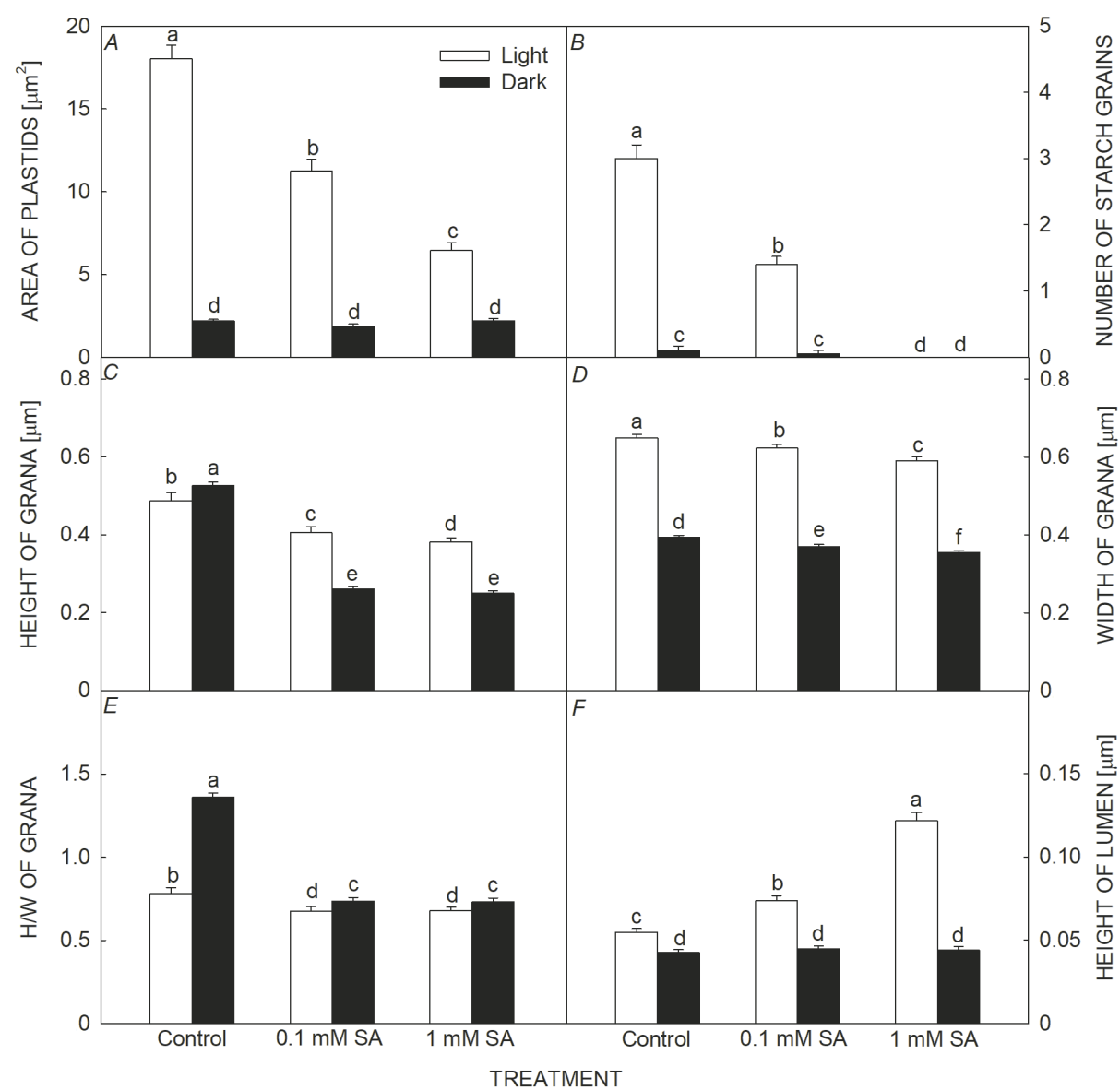

Fig. 7. Changes in the area of plastids $(A)$, number of starch grains $(B)$, height of grana $(C)$, width of grana $(D)$, ratio of height $(\mathrm{H})$ and width (W) of grana $(E)$, and height of lumen $(F)$ in grana in chloroplasts from palisade parenchyma cells of fully expanded young tomato leaves exposed to 0.1 or $1 \mathrm{mM} \mathrm{SA}$ for $24 \mathrm{~h}$ in the light or in the dark. Means \pm SE, $n=30$. Bars denoted by different letters are significantly different at $P \leq 0.05$ as determined by Duncan's multiple range test. thus it can be a model of the events associated with cell death initiation. The plants upon SA treatments exhibited much higher oxidative burst in the light than during prolonged darkness (Poór et al. 2017). Thus, the reactive oxygen species (ROS) generated by photosynthetic electron transport can account for SA effect in these plants. Our results demonstrated that the exogenous treatment with $1 \mathrm{mM}$ SA caused a significant decrease in the maximum quantum yield of PSII $\left(\mathrm{F}_{\mathrm{v}} / \mathrm{F}_{\mathrm{m}}\right)$ independently from the presence or absence of light during the treatment. Surprisingly, 0.1 mM SA had a significant effect on the open PSII RC populations by enhancing the closure of PSII RCs after 24-h dark incubation.

Earlier it was also found that SA decreased the $F_{v} / F_{m}$ parameter of Chl $a$ fluorescence in a concentrationdependent manner (Poór et al. 2011) or as a function of time (Poór and Tari 2012) and this effect of SA was dependent on increasing light intensity (Karpiński et al. 2013). However, this is the first observation that a 24-h dark incubation also influenced the effects of SA on the activity of photosynthetic electron transport chain. Furthermore, only a few studies have examined the effects of SA on PSI activity (Janda et al. 2012).

Interestingly, $\mathrm{Y}_{(\mathrm{II})}$ and $\mathrm{Y}_{(\mathrm{I})}$ were downregulated in darktreated samples by $0.1 \mathrm{mM} \mathrm{SA}$ due to a strong CEF and therefore also enhanced $\mathrm{Y}_{(\mathrm{NPQ})}$, although, this was accompanied with a significant increase in $\mathrm{Y}_{(\mathrm{NO})}$ as well. These changes occurred in parallel with higher $\mathrm{Y}_{(\mathrm{ND})}$, but
$Y_{(\mathrm{NA})}$ was unaffected, which means that $\mathrm{Y}_{(\mathrm{I})}$ downregulation has a PSII origin. CEF can provide protection against the photoinhibition of PSII by generating a proton gradient across the thylakoid membrane through transferring electrons from PSI to plastoquinone (Takahashi et al. 2009). However, CEF has an important function in the prevention of PSI photoinhibition as well, by dissipating the excess electron flow to $\mathrm{O}_{2}$, which generates superoxide anion radical. ${ }^{\circ} \mathrm{O}_{2}{ }^{-}$is then utilized by the mechanism of the water-water cycle (Ort and Baker 2002). The increase in $\mathrm{Y}_{(\mathrm{NPQ})}$ is a good indicator of the onset of photoprotective mechanisms, which are mostly related to the xanthophyll cycle and the formation of $\Delta \mathrm{pH}$ across the thylakoid membranes. Although the yield of CEF shows a positive correlation with $\mathrm{Y}_{(\mathrm{NPQ})}$ (Miyake et al. 2010, Lei et al. 2014, Zhang et al. 2014), the formation of $\Delta \mathrm{pH}$ across the thylakoid membranes and therefore the increase in $\mathrm{Y}_{(\mathrm{NPQ})}$ could be induced partially by CEFindependent mechanisms (e.g. NAD(P)H-oxidoreductase dependent chlororespiration) at high SA concentrations during darkness (Miyake et al. 2010), or by other, $\Delta \mathrm{pH}$ independent processes (Jahns and Holzwarth 2012). At the same time, $0.1 \mathrm{mM}$ SA caused only very small changes in $\mathrm{Y}_{(\mathrm{II})}$ and $\mathrm{Y}_{(\mathrm{I})}, \mathrm{Y}_{(\mathrm{NPQ})}$, and $\mathrm{Y}_{(\mathrm{ND})}$ in the light samples.

$Y_{\text {(II) }}$ and $Y_{(I)}$ were also downregulated by $1 \mathrm{mM} \mathrm{SA}$, but the decreases suggest different underlying processes in dark and light samples. In light samples, high CEFinduced NPQ protected the photosystems more efficiently. 
In contrast to this, in dark samples, CEF was slightly less efficient, and therefore $\mathrm{Y}_{(\mathrm{NO})}$ significantly increased. These observations in parallel with a slight increase in $F_{0}$ can suggest that the PSII supercomplex might be damaged. However, NPQ mechanisms can dissipate the excess energy absorbed by LHCII and in cooperation with the antioxidant system, it can alleviate the harmful effects of ROS on photosynthetic apparatus (Müller et al. 2001). Based on our results, SA treatments stimulated both $\mathrm{Y}_{(\mathrm{CEF})}$ and $\mathrm{Y}_{(\mathrm{NPQ})}$, especially in the case of $0.1 \mathrm{mM}$ SA in the dark, suggesting that there is a greater need for photoprotective mechanisms after the dark incubation. Night effect on the Chl fluorescence parameters of Norway spruce seedlings (adapted to normal photoperiod) was also investigated earlier (Roháček and Barták 1999). The authors found that after $6 \mathrm{~h}$ of darkness quenching analysis of Chl $a$ fluorescence showed an increased NPQ associated with decreased $\mathrm{q}_{\mathrm{P}}$ and $\mathrm{Y}_{\text {(II) }}$. SA-induced damage of the photosynthetic apparatus was also alleviated by enhanced photoprotection, which was more effective at the lower SA concentration in the dark. Nevertheless, under these conditions of SA exposure, contents of $\mathrm{Chl}(a+b)$ and Car did not decrease, which could have modified the Chl $a$ fluorescence parameters.

The accumulation of the photosynthetic products was also different after SA exposure in the two environments. Prolonged darkness significantly decreased starch and soluble sugar contents in the control leaves, but it was not affected further by SA. However, SA caused significant changes in carbohydrate contents in the light. SA of $1 \mathrm{mM}$ decreased starch but increased the soluble sugar content of these samples. High contents of sucrose and glucose can trigger leaf senescence (van Doorn 2008), thus the absence of starch synthesis and a concomitant accumulation of soluble sugars may contribute to the initiation of cell death by high concentrations of SA.

Chloroplast morphology was also altered after SA accumulation in barley plants (Uzunova and Popova 2000). Our results demonstrated that the effects of SA on the chloroplast structure were also dependent on the presence or absence of light. SA treatments, as a function of the applied concentration, decreased the area of chloroplasts in the light but this parameter remained constant and independent of SA under prolonged darkness. Shape and area of chloroplasts can be determined by the presence and quantity of starch grains, which were also regulated by the diurnal cycle (Gebauer et al. 2017, O'Leary et al. 2017). Interestingly, the area of chloroplasts in parallel with the number of starch grains decreased more effectively in the light, but the height of grana decreased more pronouncedly after SA exposure in the dark compared to the light. Moreover, we could observe long, wavy, deformed lumen and dilation of thylakoid membranes after $1 \mathrm{mM}$ SA treatment in the light. The structural stability and optimal size of grana are dependent on the formation of PSII-LHCII supercomplex (Kirchhoff 2014). Thus, changes in the PSII-LHCII supercomplex, such as the decrease in the number of LHCII (Kim et al. 2009) and/or decrease in the number of PSII (Iwai et al. 2014), affect the grana formation and decrease the grana size. Moreover, photosynthetic membranes are rich in the non-phosphorous and uncharged glyceroglycolipids. The two main types, monogalactosyldiacylglycerol (MGDG) and digalactosyldiacylglycerol (DGDG) play also a role in the stabilization of photosystem protein complexes in chloroplasts (Rocha et al. 2018). It has been observed recently that $1 \mathrm{mM}$ SA changed the MGDG/DGDG ratio and decreased the MGDG content in flax leaves (Linum usitatissimum L.), which can contribute to the changes in biogenesis and stabilization of chloroplast membranes (Belkadhi et al. 2015). The decrease in $\mathrm{F}_{\mathrm{v}} / \mathrm{F}_{\mathrm{m}}$ and $\mathrm{Y}_{\text {(II) }}$ upon $1 \mathrm{mM}$ SA treatment accompanied with a slight increase in $\mathrm{F}_{0}$ under both light and dark conditions suggests that the PSII supercomplex may have been damaged and/ or the turnover of D1 may have been disturbed. SA plays an important role in regulating the thylakoid membrane proteins under different environmental stresses. Interestingly, Chen et al. (2016) found that $0.25 \mathrm{mM} \mathrm{SA}$ increased the content of D1, Lhcb3, and Lhcb6, but did not change the content of Lhcb1, Lhcb2, Lhcb4, and Lhcb5 in two-week-old wheat seedlings after $24 \mathrm{~h}$. In addition, 0.3 mM SA was able to influence the turnover of D1 protein through regulating the activity of protein kinases in wheat leaves (Zhao et al. 2011). In contrast, Gao et al. (2018) observed that D1 and the major PSII and PSI proteins significantly decreased in the presence of $600 \mu \mathrm{M}$ SA in Chlamydomonas reinhardtii and SA caused the digestion of thylakoid membrane proteins. Moreover, D1 subunit is the main target of photooxidative damage (Kirchhoff 2014), which can be induced by SA in the chloroplasts (Poór and Tari 2012). Thus the potential decrease in D1 content can contribute to the decrease in grana height, which was found also in the case of light stress (Herbstová et al. 2012). Kirchhoff et al. (2011) observed in dark- and light-adapted Arabidopsis leaves that the granal thylakoid lumen significantly expanded and swelled in the light, which was prevented by a restriction imposed on protein diffusion in the dark. The swelling of the lumen could allow luminal Deg proteases to get in contact with PSII contributing to the repair of photodamaged PSII proteins (Kirchhoff 2014). In addition, Mishev et al. (2011) found that the expression of the genes for the two plastid proteases Deg1 and FtsH5 involved in D1 protein degradation was inhibited in leaves of Arabidopsis in the dark, suggesting that these proteases function mainly in illuminated leaves. These results may suggest that PSII reaction centres need higher repair capacity in the light after $1 \mathrm{mM}$ SA treatment than in the dark.

In conclusion, the effects of exogenous SA application on photosynthetic activity and on chloroplast morphology are different under normal photoperiod and after 24-h incubation in prolonged darkness. Although the treatment of tomato plants with the sublethal concentration of SA decreased the effective quantum yield in both photosystems after dark incubation, the photoprotective processes, such as the regulated and nonregulated nonphotochemical quenching in parallel with CEF, were activated effectively in the mature leaves of tomato. With the exception of CEF, low SA did not cause significant changes in these parameters under normal photoperiod. However, the low 
SA concentration exerted an influence on chloroplast morphology, such as the area of plastids, the height of grana or granal lumen, under normal photoperiod and/or during prolonged darkness. In contrast to the lower concentration, $1 \mathrm{mM}$ SA elicited an inhibition in $\mathrm{F}_{\mathrm{v}} / \mathrm{F}_{\mathrm{m}}, \mathrm{Y}_{(\mathrm{II})}, \mathrm{Y}_{(\mathrm{I})}$ in both environments, which was accompanied with less efficient photoprotection especially after 24-h dark treatment. SA of $1 \mathrm{mM}$ caused damaged chloroplast structure (abnormal shape of plastids, increased volume of grana thylakoids) but it was more pronounced in the light. In addition, chloroplasts lost their normal thylakoid arrangement and displayed damaged envelopes. Decrease in grana height, as well as dilation of thylakoids and appearance of long wavy membranes with deformed lumen were also observed in these SA-treated samples in the light which is in good agreement with our earlier finding that $1 \mathrm{mM}$ concentration of SA induced cell death in tomato leaves, which can be more considerable in the light.

\section{References}

Ballaré C.L.: Light regulation of plant defense. - Annu. Rev. Plant Biol. 65: 335-363, 2014.

Belkadhi A., De Haro A., Obregon S. et al.: Exogenous salicylic acid protects phospholipids against cadmium stress in flax (Linum usitatissimum L.). - Ecotox. Environ. Safe. 120: 102$109,2015$.

Cerrudo I., Keller M.M., Cargnel M.D. et al.: Low red/far-red ratios reduce Arabidopsis resistance to Botrytis cinerea and jasmonate responses via a COI1-JAZ10-dependent, salicylic acid-independent mechanism. - Plant Physiol. 158: 20422052, 2012.

Chandra-Shekara A.C., Gupte M., Navarre D. et al.: Lightdependent hypersensitive response and resistance signaling against Turnip Crinkle Virus in Arabidopsis. - Plant J. 45: 320-334, 2006.

Chen Y.E., Cui J.M., Li G.X. et al.: Effect of salicylic acid on the antioxidant system and photosystem II in wheat seedlings. Biol. Plantarum 60: 139-147, 2016.

Cheng D.D., Liu M.J., Sun X.B. et al.: Light suppresses bacterial population through the accumulation of hydrogen peroxide in tobacco leaves infected with Pseudomonas syringae pv. tabaci. - Front Plant Sci. 7: 512, 2016.

de Wit M., Spoel S.H., Sanchez-Perez G.F. et al.: Perception of low red:far-red ratio compromises both salicylic acid- and jasmonic acid-dependent pathogen defences in Arabidopsis. - Plant J. 75: 90-103, 2013.

Fariduddin Q., Hayat S., Ahmad A.: Salicylic acid influences net photosynthetic rate, carboxylation efficiency, nitrate reductase activity, and seed yield in Brassica juncea. Photosynthetica 41: 281-284, 2003.

Gao Y., Liu W., Wang X. et al.: Comparative phytotoxicity of usnic acid, salicylic acid, cinnamic acid and benzoic acid on photosynthetic apparatus of Chlamydomonas reinhardtii. Plant Physiol Bioch. 128: 1-12, 2018.

Gebauer P., Korn M., Engelsdorf T. et al.: Sugar accumulation in leaves of Arabidopsis sweet11/sweet 12 double mutants enhances priming of the salicylic acid-mediated defense response. - Front. Plant Sci. 8: 1378, 2017.

Genty B., Briantais J.M., Baker N.R.: The relationship between the quantum yield of photosynthetic electron transport and quenching of chlorophyll fluorescence. - Biochim. Biophys. Acta 990: 87-92, 1989.
Goodspeed D., Chehab E.W., Min-Venditti A. et al.: Arabidopsis synchronizes jasmonate-mediated defense with insect circadian behavior. - P. Natl. Acad. Sci. USA 109: 4674-4677, 2012.

Griebel T., Zeier J.: Light regulation and daytime dependency of inducible plant defenses in Arabidopsis: phytochrome signaling controls systemic acquired resistance rather than local defense. - Plant Physiol. 147: 790-801, 2008.

Habibi G.: Exogenous salicylic acid alleviates oxidative damage of barley plants under drought stress. - Acta Biol. Szeged 56: 57-63, 2012.

Hansen J., Møller I.: Percolation of starch and soluble carbohydrates from plant tissue for quantitative determination with anthrone. - Anal. Biochem. 68: 87-94, 1975.

Hayat S., Masood A., Yusuf M. et al.: Growth of Indian mustard (Brassica juncea L.) in response to salicylic acid under hightemperature stress. - Braz. J. Plant Physiol. 21: 187-195, 2009.

Hayat Q., Hayat S., Irfan M., Ahmad A.: Effect of exogenous salicylic acid under changing environment: A review. - Environ. Exp. Bot. 68: 14-25, 2010.

Herbstová M., Tietz S., Kinzel C. et al.: Architectural switch in plant photosynthetic membranes induced by light stress. - P. Natl. Acad. Sci. USA 109: 20130-20135, 2012.

Horváth E., Szalai G., Janda T.: Induction of abiotic stress tolerance by salicylic acid signaling. - J. Plant Growth Regul. 26: 290-300, 2007.

Iwai M., Yokono M., Nakano A.: Visualizing structural dynamics of thylakoid membranes. - Sci. Rep.-UK 4: 3768, 2014.

Jahns P., Holzwarth A.R.: The role of the xanthophyll cycle and of lutein in photoprotection of photosystem II. - Biochim. Biophys. Acta 1817: 182-193, 2012.

Janda K., Hideg É., Szalai G. et al.: Salicylic acid may indirectly influence the photosynthetic electron transport. - J. Plant Physiol. 169: 971-978, 2012.

Janda T., Gondor O.K., Yordanova R. et al.: Salicylic acid and photosynthesis: signalling and effects. - Acta Physiol. Plant. 36: 2537-2546, 2014.

Janda T., Szalai G., Leskó K. et al.: Factors contributing to enhanced freezing tolerance in wheat during frost hardening in the light. - Phytochemistry 68: 1674-1682, 2007.

Kangasjärvi S., Neukermans J., Li S. et al.: Photosynthesis, photorespiration, and light signalling in defence responses. - J. Exp. Bot. 63: 1619-1636, 2012.

Karpiński S., Szechyńska-Hebda M., Wituszyńska W., Burdiak P.: Light acclimation, retrograde signalling, cell death and immune defences in plants. - Plant Cell Environ. 36: 736744, 2013.

Kazan K., Manners J.M.: The interplay between light and jasmonate signalling during defence and development. - J. Exp. Bot. 62: 4087-4100, 2011.

Kegge W., Weldegergis B.T., Soler R. et al.: Canopy light cues affect emission of constitutive and methyl jasmonate-induced volatile organic compounds in Arabidopsis thaliana. - New Phytol. 200: 861-874, 2013.

Khan M.I.R., Fatma M., Per T.S. et al.: Salicylic acid-induced abiotic stress tolerance and underlying mechanisms in plants. - Front. Plant Sci. 6: 462, 2015.

Kim E H., Li X.P., Razeghifard R. et al.: The multiple roles of light-harvesting chlorophyll $a / b$-protein complexes define structure and optimize function of Arabidopsis chloroplasts: a study using two chlorophyll $b$-less mutants. - Biochim. Biophys. Acta 1787: 973-984, 2009.

Kirchhoff H.: Structural changes of the thylakoid membrane network induced by high light stress in plant chloroplasts. Philos. T. Roy. Soc. B 369: 20130225, 2014. 
Kirchhoff H., Hall C., Wood M. et al.: Dynamic control of protein diffusion within the granal thylakoid lumen. - P. Natl. Acad. Sci. USA 108: 20248-20253, 2011.

Klughammer C., Schreiber U.: Saturation pulse method for assessment of energy conversion in PS I. - Planta 192: 261268, 1994

Kramer D.M., Johnson G., Kiirats O., Edwards G.E.: New fluorescence parameters for the determination of QA redox state and excitation energy fluxes. - Photosynth. Res. 79: 209218, 2004.

Krantev A., Yordanova R., Janda T. et al.: Treatment with salicylic acid decreases the effect of cadmium on photosynthesis in maize plants. - J. Plant Physiol. 165: 920-931, 2008.

Lei Y.B., Zheng Y.L., Dai K.J. et al.: Different responses of photosystem I and photosystem II in three tropical oilseed crops exposed to chilling stress and subsequent recovery. - Trees 28: 923-933, 2014.

Lichtenthaler H.K., Wellburn A.R.: Determinations of total carotenoids and chlorophylls $a$ and $b$ of leaf extracts in different solvents. - Biochem. Soc. T. 11: 591-592, 1983.

Loake G., Grant M.: Salicylic acid in plant defence - the players and protagonists. - Curr. Opin. Plant Biol. 10: 466-472, 2007.

López-Goldar X., Sampedro L., Zas R.: Carbon starvation by light deprivation does not constrain the ability of young pines to produce induced chemical defences in response to a barkchewing herbivore. - Environ. Exp. Bot. 130: 141-150, 2016.

Mateo A., Funck D., Mühlenbock P. et al.: Controlled levels of salicylic acid are required for optimal photosynthesis and redox homeostasis. - J. Exp. Bot. 57: 1795-1807, 2006.

Mishev K., Ananiev E.D., Humbeck K.: Organ-specific effects of dark treatment on photosynthesis and the expression of photosynthesis-related genes. - Biol. Plantarum 55: 269-278, 2011.

Miyake C.: Alternative electron flows (water-water cycle and cyclic electron flow around PSI) in photosynthesis: molecular mechanisms and physiological functions. - Plant Cell Physiol. 51: 1951-1963, 2010.

Moharekar S.T., Lokhande S.D., Hara T. et al.: Effect of salicylic acid on chlorophyll and carotenoid contents of wheat and moong seedlings. - Photosynthetica 41: 315-317, 2003.

Muthamilarasan M., Prasad M.: Plant innate immunity: an updated insight into defense mechanism. - J. Bioscience 38: 433-449, 2013

Müller P., Li X.P., Niyogi K.K.: Non-photochemical quenching. A response to excess light energy. - Plant Physiol. 125: 15581566, 2001.

O'Leary B.M., Lee C.P., Atkin O.K. et al.: Variation in leaf respiration rates at night correlates with carbohydrate and amino acid supply. - Plant Physiol. 174: 2261-2273, 2017.

Ort D.R., Baker N.R.: A photoprotective role for $\mathrm{O}_{2}$ as an alternative electron sink in photosynthesis? - Curr. Opin. Plant Biol. 5: 193-198, 2002.

Panchal S., Melotto M.: Stomate-based defense and environmental cues. - Plant Signal. Behav. 12: 2021-2032, 2017.

Pancheva T.V., Popova L.P.: Effect of salicylic acid on the synthesis of ribulose-1,5-bisphosphate carboxylase/oxygenase in barley leaves. - J. Plant Physiol. 152: 381-386, 1998.

Pancheva T.V., Popova L.P., Uzunova A.N.: Effects of salicylic acid on growth and photosynthesis in barley plants. - J. Plant Physiol. 149: 57-63, 1996.

Poór P., Gémes K., Horváth F. et al.: Salicylic acid treatment via the rooting medium interferes with stomatal response, $\mathrm{CO}_{2}$ fixation rate and carbohydrate metabolism in tomato, and decreases harmful effects of subsequent salt stress. - Plant Biol. 13: 105-114, 2011.

Poór P., Takács Z., Bela K. et al.: Prolonged dark period modulates the oxidative burst and enzymatic antioxidant systems in the leaves of salicylic acid-treated tomato. - J. Plant Physiol. 213: 216-226, 2017.

Poór P., Tari I.: Regulation of stomatal movement and photosynthetic activity in guard cells of tomato abaxial epidermal peels by salicylic acid. - Funct. Plant Biol. 39: 1028-1037, 2012.

Rivas-San Vicente M., Plasencia J.: Salicylic acid beyond defence: its role in plant growth and development. - J. Exp. Bot. 62: 3321-3338, 2011.

Roberts M.R., Paul N.D.: Seduced by the dark side: integrating molecular and ecological perspectives on the influence of light on plant defence against pests and pathogens. - New Phytol. 170: 677-699, 2006.

Rocha J., Nitenberg M., Girard-Egrot A. et al.: Do galactolipid synthases play a key role in the biogenesis of chloroplast membranes of higher plants? - Front. Plant Sci. 9: 126, 2018.

Roháček K., Barták M.: Technique of the modulated chlorophyll fluorescence: basic concepts, useful parameters, and some applications. - Photosynthetica 37: 339-363, 1999.

Schreiber U., Klughammer C.: Non-photochemical fluorescence quenching and quantum yields in PS I and PS II: analysis of heat-induced limitations using Maxi-Imaging-PAM and DualPAM-100. - PAM Application Notes 1: 15-18, 2008.

Suárez-Vidal E., López-Goldar X., Sampedro L., Zas R.: Effect of light availability on the interaction between maritime pine and the pine weevil: Light drives insect feeding behavior but also the defensive capabilities of the host. - Front. Plant Sci. 8: 1452, 2017.

Takács Z., Poór P., Tari I.: Comparison of polyamine metabolism in tomato plants exposed to different concentrations of salicylic acid under light or dark conditions. - Plant Physiol. Bioch. 108: 266-278, 2016.

Takahashi S., Milward S.E., Fan D.Y. et al:: How does cyclic electron flow alleviate photoinhibition in Arabidopsis? - Plant Physiol. 149: 1560-1567, 2009.

Talapka P., Berkó A., Nagy L.I. et al.: Structural and molecular features of intestinal strictures in rats with Crohn's-like disease. - World J. Gastroentero. 22: 5154-5164, 2016.

Uzunova A.N., Popova L.P.: Effect of salicylic acid on leaf anatomy and chloroplast ultrastructure of barley plants. - Photosynthetica 38: 243-250, 2000.

van Doorn W.G.: Is the onset of senescence in leaf cells of intact plants due to low or high sugar levels? - J. Exp. Bot. 59: 1963-1972, 2008.

Vos I.A., Pieterse C.M.J., Wees S.C.M.: Costs and benefits of hormone-regulated plant defences. - Plant Pathol. 62: 43-55, 2013.

Zhang G., Liu Y., Ni Y. et al.: Exogenous calcium alleviates low night temperature stress on the photosynthetic apparatus of tomato leaves. - PloS ONE 9: doi:org/10.1371/journal. pone.0097322, 2014.

Zhao H.J., Zhao X.J., Ma P.F. et al.: Effects of salicylic acid on protein kinase activity and chloroplast $\mathrm{D} 1$ protein degradation in wheat leaves subjected to heat and high light stress. - Acta Ecol. Sin. 31: 259-263, 2011.

(C) The authors. This is an open access article distributed under the terms of the Creative Commons BY-NC-ND Licence. 